\title{
The Effect of the Crucible Rotation on the Eutectic Ceramics Preparation with Zone Melting Process
}

\author{
Zidu Li, Juncheng Liu*, Jiahao Yuan and Weinan Wang \\ School of Materials Science and Engineering, Tianjin Polytechnic University, Tianjin, 300387, P.R. China \\ *Corresponding author
}

\begin{abstract}
The alumina-based eutectic ceramic is considered as a most promising candidate materials of aviation engines due to its excellent mechanical property and high temperature oxidation resistance. Effect of the crucible rotation on the zone melting process of the eutectic ceramic is analyzed by finite element method. The results showed that: in the selected eutectic growth stages, the system desires the maximum heating power when the growth stage reaches $70 \%$, and applying crucible rotation can significantly increase the heating power of the crystal growth system; The increase of the flow field intensity will promote the heat and mass transfer process in some extent and reduce growth interface depression value obviously; with the increase of the crucible rotation speed, the melt convection intensity increases and the fluid morphology has a significant change.
\end{abstract}

Keywords-crucible rotation; eutectic ceramics; zone melting process; finite element method

\section{INTRODUCTION}

The strong demand for high temperature structural materials in the 21 st century is the major motivation for the continuous development of new materials based on multicompounds, because some of these compounds exhibit an interesting combination of high-temperature strength, oxidation resistance, optical or thermal emission properties, and so on [1-2].

The materials of aero engine turbine blade currently are mainly superalloys, of which highest working temperature is below $1100^{\circ} \mathrm{C}$ [3]. The directionally solidified eutectic ceramic is considered to be a new promising candidate material to replace the superalloys due to its excellent properties. Compared with some major fabrication methods of the eutectic ceramics, the zone melting method can reach a higher temperature gradient to obtain high performance oxide eutectic ceramics. In the directional solidification process, the control of the heat and mass transfer in the liquid phase and the solidliquid interface is very important to the crystal growth system [4].

A flat interface is optimum through the zone melting process because a concave or convex interface may cause stress, crack, non-uniform impurities and bubbles [5]. Interface shape depends mainly on the hydrodynamics of the melt and the heat transfer of the whole system [6]. There are certain difficulties to predict and explain the evolution in the zone-melting process by the experimental method. Many researchers have studied the directional solidification process with numerical simulation method. Li etc. [7] simulated the evolution of the natural convection and the solid-liquid interface shape during the directional solidification process. The result show that: with the casting speed increases from 6 $\mathrm{mm} / \mathrm{min}$ to $24 \mathrm{~mm} / \mathrm{min}$, the flow intensity of the vortex upward the center of the growth interface became stronger and the curvature of the interface has a significant increase. Sun etc. [8] studied the effect of the forced convection and the natural convection on the dendritic growth behavior. The results show that the convection accelerated the dendrite growth in the upstream direction and inhibit the growth in the downstream direction, forming a non-symmetrical dendritic morphology. Chen etc. [9] developed a zone melting model to simulate the growth of $\mathrm{Bi}_{2} \mathrm{Te}_{3}$ columnar crystals. The results indicate that a high heating temperature and a low movement speed for the heater and the cooling devices should be used to obtain stable molten zone,. The solidification interfaces were convex for a heater movement speed of $0.75 \mathrm{~cm} / \mathrm{h}$. Such interfaces were predicted to lead to larger columnar grains at the tail section. The shape of the solidification interface became level at a movement speed of $1.25 \mathrm{~cm} / \mathrm{h}$, allowing slender and straight columnar crystals to easily grow.

In order to obtain high-quality eutectic ceramic, the directional solidification process will be simulated by the FEM method to study the effect of crucible rotation speed on the flow field and temperature field of the $\mathrm{Al}_{2} \mathrm{O}_{3} / \mathrm{MgAl}_{2} \mathrm{O}_{4}$ eutectic ceramics.

\section{Simulation Modul}

The schematic view of the simulation model for the zone melting growth system is shown in Fig 1. The growth process is realized by the slow temperature profile moves upwards. The dissolution interface hits the hotter section of the temperature and dissolves the source material. This dissolution provides constantly the needed material to the liquid solution. At the same time, the growth interface hits the cooler section and the supersaturated solution in the vicinity of the growth interface solidifies on the crystals. Numerical simulation for the system needs to make some reasonable simplification as follows: The effect of the magnetic induction on the temperature distribution was ignored. A fixed temperature, $2100^{\circ} \mathrm{C}$, is applied at the crucible wall with the same height of the induction coil as the equivalent induction heating effect. 


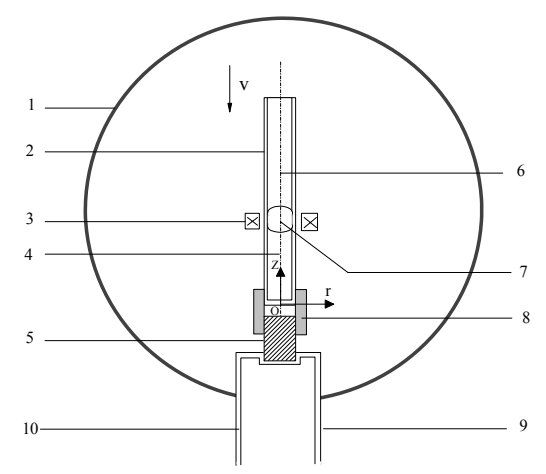

1-FURNACE; 2-CRUCIBLE; 3-INDUCTION COIL; 4-EUTECTIC CERAMICS; 5-CORUNDUM; 6-PRE-SINTERED SOURCE; 7-MELTING ZONE; 8-MOLYBDENUM; 9-STRUT; 10-FLUME

FIGURE I. SCHEMATIC VIEW OF THE ZONE-MELTING GROWTH SYSTEM

A calculation model of radiation heat transfer between outer wall of the crucible and the furnace has been built. The physical parameters of the adopted materials are isotropic, regarded as a function of temperature.

The energy equations of the melt zone, eutectic ceramics and crucible are shown as follows:

$$
\begin{gathered}
\rho_{m} C_{p, m} \frac{\partial T}{\partial t}+\rho_{m} C_{p, m}(\vec{u} \cdot \nabla) T=\nabla\left(k_{m} \nabla T\right) \\
\rho_{\mathrm{c}} C_{p, c} \frac{\partial T}{\partial t}=\nabla\left(k_{c} \nabla T\right) \\
\rho_{\mathrm{a}} C_{p, a} \frac{\partial T}{\partial t}=\nabla\left(k_{a} \nabla T\right)
\end{gathered}
$$

$\vec{u}, \mathrm{k}, \rho$, c are the velocity vector, thermal conductivity, density and specific heat.

The right boundary of temperature field is the symmetry axis. The heat transfer between the furnace and the crucible follows the radiation form, and the heat flux is calculated as:

$$
q_{12}=\varepsilon \sigma F_{12}\left(T_{1}^{4}-T_{2}^{4}\right)
$$

Where $\mathrm{T} 1$ is the surface temperature of the crucible and $\mathrm{T} 2$ the temperature of the inner surface of the furnace. $\sigma, \varepsilon, F 12$ are the Boltzman constant, radiation coefficient and view factor.2.3 Latent heat of the crystallization process

The ceramic solidification process is accompanied with the release of latent heat. This part of the energy has a significant impact on the crystal growth process. The latent heat of crystallization is equivalent to an internal heat source during the solidification process. An enthalpy method of solving phase change problems can be used for this process, assuming latent heat release within $0.10 \mathrm{C}$.

$$
\Delta H(T)=\int_{t_{1}}^{t_{2}} \rho C(t) d t
$$

In the model the liquid solution is assumed to be an incompressible, Newtonian viscous liquid, and the flow in the liquid solution is laminar. The melt flow field meets the Navier-Stokes equations, so the Continuity equations are taken as follows:

$$
\begin{gathered}
\frac{\partial u}{\partial t}+u \frac{\partial u}{\partial r}+w \frac{\partial u}{\partial x}=-\frac{1}{\rho} \frac{\partial p}{\partial r}+\frac{\mu}{\rho}\left(\frac{\partial^{2} u}{\partial r^{2}}+\frac{\partial^{2} u}{\partial x^{2}}+\frac{1}{r} \frac{\partial u}{\partial r}-\frac{u}{r^{2}}\right)+\frac{v^{2}}{r} \\
\frac{\partial v}{\partial t}+u \frac{\partial v}{\partial r}+v \frac{\partial v}{\partial x}=-g-\frac{1}{\rho} \frac{\partial p}{\partial x}+\frac{\mu}{\rho}\left(\frac{\partial^{2} v}{\partial r^{2}}+\frac{\partial^{2} v}{\partial x^{2}}+\frac{1}{r} \frac{\partial v}{\partial r}\right) \\
\frac{\partial w}{\partial t}+u \frac{\partial w}{\partial r}+v \frac{\partial w}{\partial x}=\frac{\mu}{\rho}\left(\frac{\partial^{2} w}{\partial r^{2}}+\frac{\partial^{2} w}{\partial x^{2}}+\frac{1}{r} \frac{\partial w}{\partial r}-\frac{w}{r^{2}}\right)-\frac{u w}{r}
\end{gathered}
$$

Where $\mathrm{u}, \mathrm{v}$ and $\mathrm{w}$ are the velocity components in the radial, vertical and circumferential directions, respectively.

The continuity equation of the fluid flow is as follow:

$$
\frac{\partial u}{\partial r}+\frac{\partial v}{\partial z}+\frac{u}{r}=0
$$

The rigid no-slip boundary condition was applied at solidliquid interface.

$$
u=0, v=0, \omega=\omega_{a}, \frac{\partial p}{\partial z}=0, \frac{\partial F}{\partial z}=0 .
$$

$\omega \mathrm{a}$ is the crucible speed.

The right boundary of the flow field is the symmetry axis, rigid free-slip boundary condition, and the left side of the flow field is set to be a rigid non-slip boundary condition.

$$
\begin{aligned}
& u=0, \frac{\partial v}{\partial r}=0, \omega=0, \frac{\partial p}{\partial r}=0, \frac{\partial F}{\partial r}=0 . \\
& u=0, v=0, \omega=\omega_{a}, \frac{\partial p}{\partial r}=0, \frac{\partial F}{\partial r}=0 .
\end{aligned}
$$

The materials' physical properties of the growth system were listed in table 1 . In order to study the effect of the crucible rotation speed on the directional solidification process, four examples was set as the following table 2 . 
TABLE I. THE MATERIALS' PHYSICAL PROPERTIES

\begin{tabular}{ccccc}
\hline & $\begin{array}{c}\text { Density } \\
\boldsymbol{\rho}\left(\mathbf{K g} / \mathbf{m}^{\mathbf{3}}\right)\end{array}$ & $\begin{array}{c}\text { Thermal } \\
\text { conductivity } \\
\lambda \mathbf{~ W} /\left(\mathbf{K g} \cdot{ }^{\circ} \mathrm{C}\right)\end{array}$ & $\begin{array}{c}\text { Specific } \\
\text { heat } \boldsymbol{C} \\
\mathbf{J} /\left(\mathbf{K g} \cdot{ }^{\circ} \mathrm{C}\right)\end{array}$ & $\begin{array}{c}\text { Emissivity } \\
\boldsymbol{\varepsilon}\end{array}$ \\
\hline $\mathrm{Mo}$ & 10220 & $118+0.03 \mathrm{~T}-$ & $589-0.489 \mathrm{~T}+$ & $0.1 \sim 0.3$ \\
$1.8^{*} 10^{-4} \mathrm{~T}^{2}$ & 0.1 \\
$\mathrm{Al}_{2} \mathrm{O}_{3} / \mathrm{MgAl}_{2} \mathrm{O}_{4}$ & 3580 & 5.9 & 836 & 0.9 \\
$\mathrm{C}$ orundum & 3600 & 21 & 800 & 0.9 \\
$1 \mathrm{Cr} 18 \mathrm{Ni9Ti}$ & 7850 & $12.1 \sim 27.8$ & $502 \sim 692$ & $0.36 \sim 0.44$ \\
Copper coil & 8920 & 336 & 394 & 0.8 \\
\hline
\end{tabular}

TABLE II.PARAMETERS OF THE NUMERICAL EXAMPLES

\begin{tabular}{cccc}
\hline & $\begin{array}{c}\text { Inside radius of } \\
\text { crucible }(\mathbf{c m})\end{array}$ & $\begin{array}{c}\text { The maximum crucible } \\
\text { wall temperature }\left({ }^{\circ} \mathbf{C}\right)\end{array}$ & $\begin{array}{c}\text { Crucible rotation } \\
\text { speed (rpm) }\end{array}$ \\
\hline $\mathrm{a}$ & 0.5 & 2100 & 0 \\
$\mathrm{~b}$ & 0.5 & 2100 & 5 \\
$\mathrm{c}$ & 0.5 & 2100 & 10 \\
$\mathrm{~d}$ & 0.5 & 2100 & 15 \\
\hline
\end{tabular}

\section{RESULTS AND DISCUSSION}

\section{A. The Effect of the Crucible Rotation on the Heating}

\section{Power of the Eutectic Ceramics Growth System}

According to Figure 2 it can be known, with the eutectic growth process proceeds, the required heating power reaches the maximum when their growth stages reach $70 \%$. When the growth stage reaches $70 \%$, the required heating power values of the four examples are $24.01 \mathrm{KW}, 24.10 \mathrm{KW}, 24.21 \mathrm{KW}$, and $24.43 \mathrm{KW}$ respectively. With the crucible rotation speed increases from $0 \mathrm{rpm}$ to $15 \mathrm{rpm}$, the heating power of the eutectic ceramic growth furnace increases obviously. The increase of the crucible rotation speed leading to an enhancement of the heat and mass transfer process, so the energy loss becomes faster.

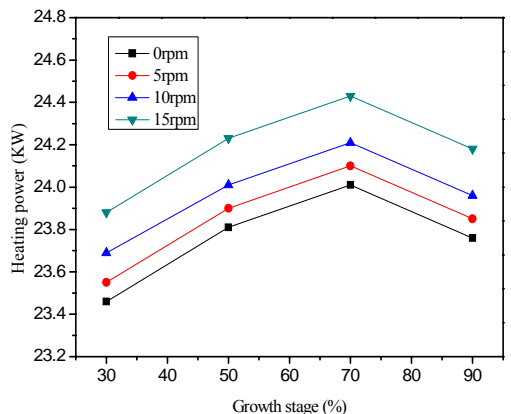

FIGURE II. THE EFFECT OF CRUCIBLE ROTATION SPEED ON THE SYSTEM HEATING POWER
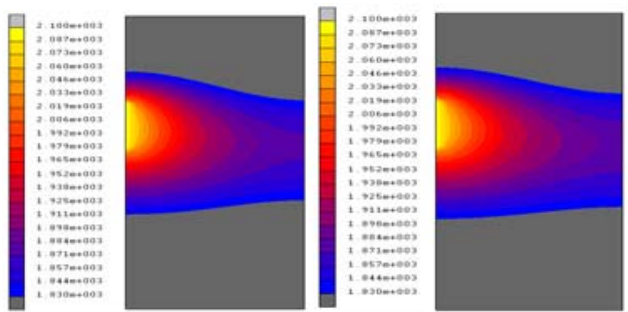

(a)

(b)

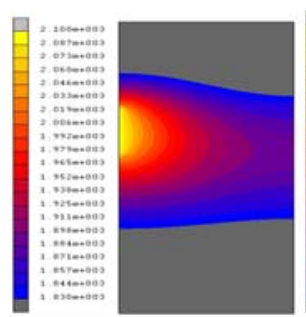

(c)

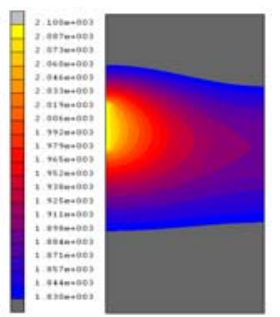

(d)
FIGURE III. TEMPERATURE FIELDS OF THE FOUR EXAMPLES WHEN THE SOLIDIFICATION STAGES REACH 30\%

\section{B. The Effect of the Crucible Rotation on the Temperature Field of the Eutectic Ceramics Growth System}

The temperature fields of zone-melting growth system reached $30 \%$ with different crucible rotation speeds are shown in Figure 3. The gray area above the melting is source materials and the gray area below the melting area is eutectic ceramics. The interface between the melt zone and the source material is the dissolution interface, and the interface between the melt zone and eutectic ceramics is the growth interface.

The growth interfaces of the four examples were depressed to the melting zone, the depression points fall on the center axis of the melt zone. The growth interfaces depression values are $0.95 \mathrm{~mm}, 0.82 \mathrm{~mm}, 0.68 \mathrm{~mm}, 0.58 \mathrm{~mm}$ with the crucible rotation speed changes $0 \mathrm{rpm}$ from to $15 \mathrm{rpm}$. With the crucible rotation speed increases within the set range, the growth interface become flatter, this would be beneficial to the crystal growth process.

\section{The Effect of the Crucible Rotation on the Growth Interface of the Eutectic Ceramics Growth System}

Depression values of the solidification interface with different crucible rotation speeds are shown in Figure 4. As the crucible rotation is applied, the depression value of the growth interface is significantly reduced. With the crucible rotation speed increases from $0 \mathrm{rpm}$ to $15 \mathrm{rpm}$, the depression value of the growth interface shows a decreasing tendency. When the crucible rotation speed is $15 \mathrm{rpm}$, the growth interface depression values of the four stages are $0.58 \mathrm{~mm}, 1.23 \mathrm{~mm}$, $1.40 \mathrm{~mm}$ and $1.26 \mathrm{~mm}$, the average value of which is $1.12 \mathrm{~mm}$, about $75 \%$ of the average value when the crucible rotation speed is $0 \mathrm{rpm}$. Therefore, it can be shown that applying the crucible rotation speed can effectively reduce the depression value of the crystal growth interface.

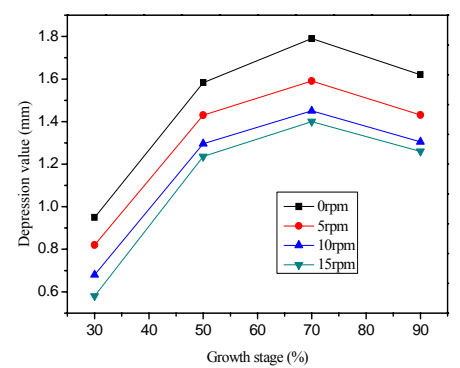

FIGURE IV. EFFECT OF THE CRUCIBLE SPEED ON THE DEPRESSION VALUE OF THE SOLIDIFICATION INTERFACE 
D. The Effect of the Crucible Rotation on the Flow Field of the Eutectic Ceramics Growth System

The calculated flow vector field and flow intensity field with different crucible rotation speeds when the growth systems reach to $30 \%$ are shown in Figure 5 and Figure 6 respectively, the unit of the flow field intensity is " $\mathrm{cm} / \mathrm{s}$ ".

As can be shown from Figure 5, the flow field of the melt includes a clockwise convection cell near the crucible wall and a counterclockwise convection cell close to the axis of the computation area. As can be shown in Figure6, the velocity intensity of the counterclockwise convection cell is significantly stronger than the clockwise convection cell. The contact position of the two convection cell exhibits the strongest velocity intensity because of the combined action of the two convection cells. The maximum flow field velocity increases from $2.75 \mathrm{e}-4 \mathrm{~cm} / \mathrm{s}$ to $9.76 \mathrm{e}-4 \mathrm{~cm} / \mathrm{s}$ with the crucible rotation speed changes from $0 \mathrm{rpm}$ to $15 \mathrm{rpm}$. With the increase of the crucible rotation speed, the velocity intensity of the counterclockwise convection cell is significantly stronger than that of the clockwise convection cell. The area occupied by the counterclockwise convection cell increases and the area occupied by the clockwise convection cell is squeezed correspondingly. The convection intensity of the flow field become stronger with increase of the crucible rotation speed during the directional solidification process, the result leads to a higher intensity of the heat and mass transfer, simultaneously the thermal vibration of the growth interface became severer. So the uniformity of the crystalline component and the completeness of the crystal may be affected.

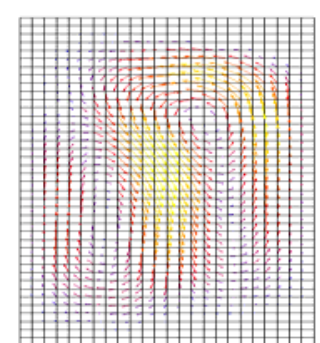

(a)

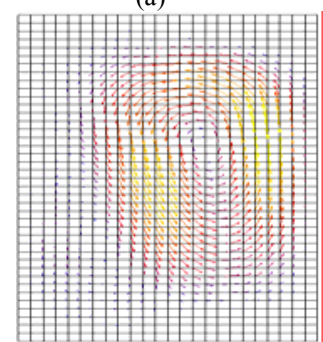

(c)

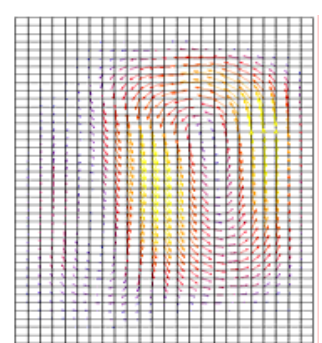

(b)

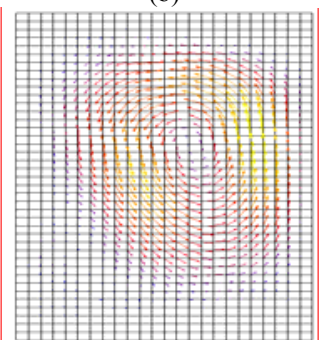

(d)
FIGURE V. FLUID VECTOR FIELDS OF THE FOUR EXAMPLES WHEN THE SOLIDIFICATION STAGES REACH 30\%

\section{CONCLUSION}

Effect of the crucible rotation on the zone melting process of the $\mathrm{Al}_{2} \mathrm{O}_{3} / \mathrm{MgAl}_{2} \mathrm{O}_{4}$ eutectic ceramic is analyzed by the finite element method. The main conclusions are as follows:
In the eutectic ceramics growth process, when the crucible rotation is applied, the required heating power needs to be increased for maintaining the temperature at a constant value. The required heating power reaches the maximum value when the growth stage is $70 \%$.

The depression values of the four examples reach the maximum value when the growth process reaches $70 \%$. Applying the crucible rotation can effectively reduce the depression value of the crystal growth interface.

When the growth process stage reaches $30 \%$, the flow field includes a clockwise convection cell near the crucible wall, and a counterclockwise convection cell close to the axis of the calculation area. The integral intensity of the flow field becomes stronger with the crucible rotation speed increases during solidification process.

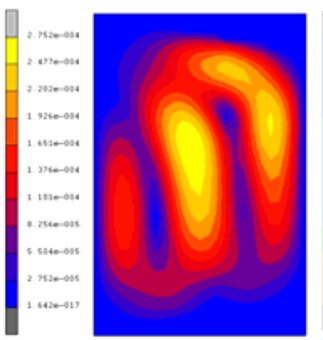

(a)

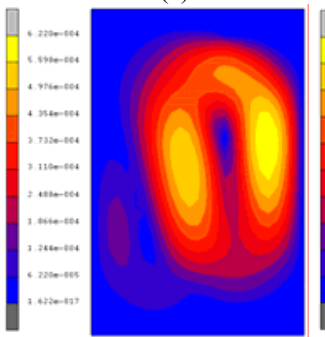

(c)

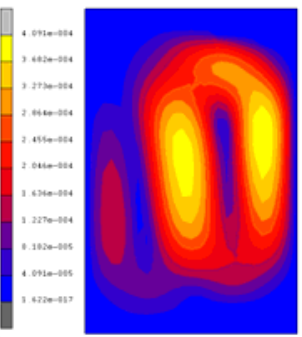

(b)

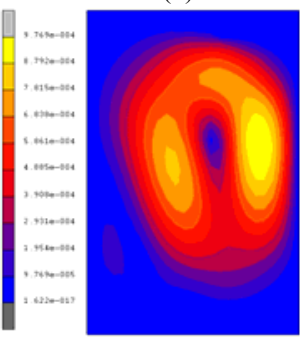

(d)
FIGURE VI. FLUID VELOCITY FIELDS OF THE FOUR EXAMPLES WHEN THE SOLIDIFICATION STAGES REACH $30 \%$

With the increase of the crucible rotation speed, the flow field intensity increases and the fluid morphology has a significant change. The increase of the flow field intensity will promote the heat and mass transfer process in some extent and reduce growth interface depression value obviously.

\section{ACKNOWLEDGEMENTS}

This work was financially supported by the Natural Science Foundation of China (NSFC), Grant No. 51172161.

\section{REFERENCES}

[1] Hashimoto S, Nishina N, Hirao K, et al. Formation mechanism of Ti2AlC under the self-propagating high-temperature synthesis (SHS) mode[J]. Materials Research Bulletin, 2012, 47(5): 1164-1168.

[2] Lakiza S M, Tyschenko J S, Lopato L M. Phase diagram of the Al2O3HfO2-Y2O3 system [J]. Journal of the European Ceramic Society, 2011, 31(7): 1285-1291.

[3] James C Williams, Edgar A Starke Jr. Progress in structural materials for aerospace systems [J]. Acta Materialia, 2003, 51(19): 5775-5799. 
[4] Dost S, Liu Y C. Controlling the growth interface shape in the growth of CdTe single crystals by the traveling heater method [J]. Comptes Rendus Mecanique, 2007, 335(5): 323-329.

[5] S Haitao. Preparation and properties of Al2O3/MgAl2O4 infraraed transparent ceramics [D]. Harbin: Harbin Institute of Technology, 2011

[6] Wu X B, Geng X, Guo Z Y. Fundamental Study of Crystal/Melt Interface Shape Change in Czochralski Crystal Growth [J]. J. Crystal Growth, 1996, 169: 786-794.

[7] L Xiangmei, Z Jieyu, W Bo, et al. The simulation of natural convection and solid-liquid interface shape in directionally solidification process for superalloy [J].the chinese journal of process engineering. 2010, 10(1): 252-255.

[8] S Dongke, Z Mingfang, Y Chaorong. Numerical simulation of the dendrite growth under the forced convection and natural convection. Acta Physica Sinica. 2009, 58(13): 285-291.

[9] Chen Y R, Hwang W S, Hsieh H L, et al. Thermal and microstructure simulation of thermoelectric material $\mathrm{Bi} 2 \mathrm{Te} 3$ grown by zone-melting technique[J]. Journal of Crystal Growth, 2014, 402(12):273-284 